\title{
Blockchain technology's impact on supply chain integration and sustainable supply chain performance: evidence from the automotive industry
}

\author{
Sachin S. Kamble ${ }^{1} \cdot$ Angappa Gunasekaran $^{2} \cdot$ Nachiappan Subramanian $^{3}$ (D) \\ Abhijeet Ghadge $^{4} \cdot$ Amine Belhadi $^{5} \cdot$ Mani Venkatesh $^{6}$
}

Accepted: 21 May 2021

(C) The Author(s) 2021

\begin{abstract}
The study investigates the relationship between the information and communication-enabled supply chain integration (SCI) and sustainable supply chain performance (SSCP). Moreover, to the best of our knowledge, there is no empirical evidence on the impact of blockchain technologies (BT) on the SSCP. Therefore, the primary aim of this study is to assess the relationship between BT and SSCP. More specifically, the study was conducted to examine the direct influence of BT on SCI and SSCP and the interactive effect of BT and SCI on SSCP. Based on the dynamic capability theoretical lens, the present study conceptualizes the use of BT as a specific IT resource to collaborate and reconfigure the ties with the upstream and downstream supply chain members to achieve SSCP. The results of the study support the hypothesis stating that BT positively influences the SSCP. The results recognize the role of SCI as a significant mediating variable between the BT and SSCP. The result indicates the strong influence of SCI with full mediation effect on the relationship between the BT and SSCP.
\end{abstract}

Keywords Blockchain - Supply chain integration - Supply chain performance $\cdot$ Automotive sector $\cdot$ Economic sustainability

\section{Introduction}

The automotive sector is one of the driving forces of the Indian economy, contributing about $49 \%$ to the country's manufacturing gross domestic product (GDP) and employing over 32 million workforces (Economic Times, 2020). Indian automotive industry is the fourth largest manufacturer of commercial vehicles globally and is classified into four segments: two-wheeler, passenger car, commercial vehicles, and tractors (Sahoo \& Rath, 2018). With the vast potential for electric and autonomous cars, India is expected to become a world leader in shared mobility by 2030 (IBEF, 2018). The automotive sector is highly competitive and challenging, under pressure to continuously improve its sustainable

Nachiappan Subramanian

N.Subramanian@sussex.ac.uk

Extended author information available on the last page of the article 
supply chain performance (SSCP) (Nassar et al., 2019; White, 2017). Achieving SSCP needs the firms to be innovative in providing value to their customers.

The recent developments in the field of information and communication technologies (ICT) have demonstrated ICT intervention is a promising approach to make the Supply chain (SC) processes more efficient (Queiroz \& Wamba, 2019). Besides, previous studies have found that ICT increases SC integration (SCI) to handle a substantial increase in volume and complexities of information between various SC partners (Prajogo \& Olhager, 2012). There is also a prediction that ICT-enabled Industry 4.0 technologies will augment process integration, resulting in sustainable organizational performance $(\mathrm{Lu} \&$ $\mathrm{Xu}, 2017$; Kamble et al., 2018). Specifically, the study's sustainability focus is on defectfree operations on the upstream and downstream sides. Today's organizations are consistently searching for innovative ways to integrate ICT into their business process to acquire sustainable benefits (Carrera \& Kurnia, 2015; Centobelli et al., 2020).

Blockchain is a prominent technology with the vast potential to resolve the SC complexities (Hofmann et al., 2018; Ivanov et al., 2018; Kamble et al., 2018; Nayak \& Dhaigude, 2019; Queiroz \& Wamba, 2019; Viryasitavat et al., 2020). Blockchain Technology (BT) is an organizational capability that integrates all the SC assets and resources, adding value to the activities such as product tracking, information sharing, and providing transparency in SC transactions (Aste et al., 2017; Korpela et al., 2017; Pazaitis et al., 2017). BT builds trustworthiness and reliability in the SC network when integrated with the other cutting edge technologies such as cloud computing (Liu \& Xu, 2017), robotics system (Mueller et al., 2017), Internet of Things (IoT) (Yang et al., 2017), big data analytics (Belhadi et al., 2019; Lee et al., 2017), cybersecurity (Yu et al., 2017) and simulations and prototype (Ramadan et al., 2017). BT is expected to have a significant impact on the SC processes in the context of the automotive industry (Chen, 2018).

Although previous studies justified the investments made in ICT improves SCI and supply chain performance (SCP) (Vanpoucke et al., 2017; Zhou et al., 2015), others have found that these investments have failed to create a sustained impact on the organizational performance (Rehman \& Hussain, 2013). Inconsistencies in the findings motivate us further to investigate the relationship between the ICT-enabled SCI and SSCP. Moreover, to the best of our knowledge, there is no empirical evidence on the impact of BT on the SSCP. SCI is a significant factor in improving partnership and collaboration among the SC participants (Prajogo et al., 2016). BT provides secured storage of all the SC transactions, easily accessible to all the SC partners, thereby improving SCI level (Biswas et al., 2017). Previous studies have also identified SCI as a significant mediating variable in the SSCP literature, subject to various independent and dependent variables (Flynn et al., 2010; Prajogo \& Olhager, 2012; Rai et al., 2006; Zhu et al., 2017). BT has the potential to enhance the SCI, contributing towards business excellence and sustainability. Hence, this study also undertakes an empirical investigation of SCI's role as a mediating variable in the relationship between BT and SSCP. Therefore, the primary aim of this study is to assess the relationship between BT and SSCP. More specifically, the study was conducted to examine BT's direct influence on SCI and SSCP and the interactive effect of BT and SCI on SSCP.

Adopting the dynamic capabilities theory, the study conceptualizes BT as a dynamic capability and explores its direct influence on SCI and indirect influence on SSCP. The data to answer the above research question was collected through a questionnaire survey conducted with 253 managers from the Indian automotive industry. The remaining of the paper is organized as follows: Sect. 2 presents the discussion on theoretical background and hypotheses development. Section 3 presents the details of the research methodology. 
Section 4 discusses the findings of the study. The conclusions, implications, and limitations of the study are discussed in Sect. 5.

\section{Theoretical background and hypothesis development}

\subsection{Blockchain in the automotive industry}

A recent study by IBM (2020) reported that $62 \%$ of practitioners in the automotive industry perceived that Blockchain would be a disruptive force in the automobile industry by 2021 . However, India's automobile industry has been slow in leveraging the technology due to various reasons but is slowly gaining momentum to grab the emerging opportunities (Kamble et al., 2018). The recent developments in the global automobile industry have forced the Indian government to develop a long-term regulatory roadmap for the automobile industry (FRPT, 2020a). The government plans to bring the Indian automotive industry at par with developed nations in safety and emission regulations. Further, the developments in connected technologies such as GPS tracking, dash camera, telematics-based insurance, and SOS services will, in turn, drive the growth of intelligent vehicles, demanding clarity on the government rules and regulatory frameworks (FRPT, 2020b). The present study's findings will help the Indian policy makers and the supply chain practitioners develop relevant policies for the Indian automotive industry, taking into consideration its linkages with the supply chain integration and supply chain performance.

The new wave of digital transformation has forced Indian automobile companies to innovate and adopt new technologies. The automobile companies must change their focus from selling price optimization to life cycle cost optimization, building competitive advantage and opening new business opportunities (Kamble et al., 2018).

\subsection{Dynamic capabilities theory}

"Capability is considered dynamic when it enhances the firm's ability to make decisions, solve problems, identify opportunities and threats, and modify existing resources" (Barreto, 2010; Eisenhardt \& Martin, 2000; Teece et al., 1997). Perks et al. (2017) claims that BT in SCs brings together all the SC partners to co-create value by performing their assigned task, achieved through the dynamic configuration of SC resources. Dynamic capability is defined as "the capacity of an organization to create, extend, and modify its resource base purposefully" (Helfat \& Winter, 2011, p 4). Following the dynamic capability theory, it is believed that organizations can create 'value' by modifying SC processes and resources. BT's principal value drivers include increased transparency, immutability, ledger privacy, reliability, and trustworthiness (Kamble et al., 2018). These value drivers are expected to reduce transaction-based costs, add new services, delineate the organizational boundaries and automate and decentralize the SC decision making (Angelis \& da Silva, 2018; Pereira et al., 2019).

The use of BT in SC is perceived to improve the productivity and performance of the organizations through hyper-levels of SCI, end-to-end integration of product and process data (Wang et al., 2019). Polim et al. (2017) also suggest Blockchain as a technology with high information integration capability. In this study, BT is considered as a dynamic capability "that provides the ability to integrate, build, and reconfigure internal and external competencies to address rapidly changing environments" (Teece et al., 1997). Further, the 
literature on organizational capability reveals that the firm's internal integration and external integration are associated with each other leading to performance improvements (Huo, 2012), encouraging us to select the construct of SCI in the present study.

\subsection{Blockchain technology (BT)}

BT is defined as a "distributed, shared, encrypted database that serves as an irreversible and incorruptible repository of information" (White, 2017). The blockchain principle works on the distributed ledger, information synchronization, information access, and user validation (Kano \& Nakajima, 2018). Other researchers consider BT as an ICT-enabled SCI innovation that integrates several other ICT technologies such as software development tools, cryptographic technology, database technology, and data analytics (Mougayar, 2016). In a supply chain, BT provides a high level of integration and acts as a single source of information to all the SC partners (Korpela et al., 2017). BT supports all the SC domains that include planning, procurement, manufacturing, and delivery (Kamble et al., 2018). BT provides organizations with increased SC visibility and transparency in transactions (Ivanov et al., 2018).

Moreover, BT applications can help track the organizations' purchase activities (Hofman et al., 2018) for negotiating better quantity discounts (Joshi, 2017). BT helps the organizations in SC risk mitigation by developing accurate demand forecasts and SC resources management (Ivanov et al., 2018). In the manufacturing domain, BT can monitor and validate the manufacturing parameters (Shanley, 2017; Subramanian et al. 2020).

Industry 4.0 technologies are data-driven, generating a massive amount of data for making effective decisions. BT can be used to leverage the big data generated from industry 4.0 technologies (Jeschke et al., 2017). The additive manufacturing integrated with BT leads to better process documentation, improving the product design features (Holland et al., 2017). BT can improve the SC participants' efficiency by standardizing and distributing the quality documentation processes across all the SC (Kamble et al., 2020). Wipro has developed a BT application to identify and eliminate counterfeit items, thereby providing a high product transparency level (Wipro, 2017). In logistics and transportation, the significant contribution from BT can be in the form of vehicle tracking and freight management (Winnesota, 2017). Even though the organizations are aware of the benefits provided by the BT, the full-fledged deployment in the SC is far from reality (Kamble et al., 2018). Angelis and da Silva (2018) suggest that organizations' decision to adopt Blockchain should not be based on the hype surrounding the benefits of BT, but the value the Blockchain will provide to the organization. In this study, we measure the impact of BT adoption on SSCP in the Indian automotive sector, which is sharply shifting to digitalization, thereby changing the entire business model. Recent studies emphasized that many automotive industries and stakeholders have used the BT in autonomous vehicles, cybersecurity, and connected cars to achieve scalability, auditability, and real-time monitoring (Belhadi et al., 2020). Manufacturing industries, supply chain logistics, retailing, and leasing are some of the automotive industry's key functional areas which can be leveraged through blockchain technology (Upadhyay et al., 2021).

\subsection{Supply chain integration $(\mathrm{SCl})$ in the automotive sector}

SCI is a widely researched topic in supply chain management that aims to provide increased value to the end customers. SCI has three dimensions, namely, "process integration" (PI), 
"supplier integration" (SI), and "customer integration" (CI) (Alfalla-Luque et al., 2013; Ataseven \& Nair, 2017; Näslund \& Hulthen, 2012). The three SCI dimensions are further categorized into two main components; external (SI and CI) and internal integration (II) (Flynn et al., 2010). CI refers to "the degree to which a firm collaborates with its customers to improve visibility and enable mutual planning" (Wong et al., 2011). CI embraces the bi-directional flow of information, service, and materials between the focal company and customers; it also includes information flowing from customers to the focal company. CI helps the organizations develop accurate demand forecasts, adapt to demand fluctuations, implement JIT delivery systems and postponement strategies (Flynn et al., 2010; Dong et al., 2001; Van Hoek, 1999). SI refers to "the degree to which firm partners with its suppliers to structure their inter-organizational practices, procedures, strategies, and behaviors into a synchronized and manageable process to fulfill customer's requirements at the lowest cost and quick deliveries" (Flynn et al., 2010; Zhao et al., 2008). SI enhances knowledge sharing, reducing the uncertainty, transaction costs (Williamson, 1989), inventory costs, and the bullwhip effect (Lee et al., 1997). PI provides easy access to the firm's integrated database (Zhao et al., 2008), interconnecting all the focal firm departments with a highly integrated information system (Mackelprang et al., 2014). PI provides all the departments access to real-time information helpful in tracking and retrieving inventory status throughout the SC (Alfalla-Luque et al., 2013). The studies have identified that the PI improves the upstream supplier and downstream customer integration (Huo, 2012). In this study, we examine the role of both the internal and external SCI dimensions, as Blockchain technology adoption (BTA) in a manufacturing firm is intended to synchronize the flow of products and information within and across the supply chains.

The customers' value is provided through the effective and efficient flow of finance, product, and information through inter-and intra-organizational collaboration on strategic, tactical, and operational dimensions of business processes (Alfalla-Luque et al., 2013; Huo, 2012; Yu et al., 2015; Zhao et al., 2011). SCI is achieved through the involvement of upstream and downstream stakeholders and digitally links them to the business processes within and between the organizations (Ataseven \& Nair, 2017). SCI's role has been extensively studied in the literature and is found to be a significant variable affecting the SC and firm performance (Flynn et al., 2010; Prajogo \& Olhager 2012, Zhu et al., 2017).

Particularly in the automotive sector, value is generated through transactions and contracts in business networks that create a flow of goods and services. The underlying markets could include open markets such as a car auction or a private market such as a supply chain financing. In every case, assets are transferred across the business network between the different stakeholders. For that reason, firms within the automotive industry, which are always on the lookout for capabilities, technologies, and strategies enabling them to enhance SC performance (Upadhyay et al., 2021), have to be synchronized with each other within the automotive SC, thereby developing SCI.

\subsection{Sustainable supply chain performance (SSCP) in the automotive sector}

SSCP plays a significant role in the successful functioning of an organization. The timely and efficient evaluation of the supply chains helps in strategy formulation, implementation, and monitoring (Gawankar et al., 2017). With the increasing scope and extensive activities of the supply chains, tracing the events is becoming a significant challenge. The customers and buyers will appreciate the real value of the products or services if the supply chains offer transparency and provide details of the various historical incidents linked with the 
product and services (Dickson, 2016). The SC's transformation towards a digital eco-system requires that the existing interdependencies between the SC partners are modified, and information access is opened to all the SC participants. All the SC partners become equally crucial for successfully integrating collective value creation and shared responsibility (Kamble et al., 2018). Most of the previous studies that deal with sustainable supply chains have emphasized the inclusion of economic, environmental, and social dimensions of sustainability (Belhadi et al., 2020; Carter \& Rogers, 2008; Formentini \& Taticchi, 2016).

In the present study, we have focused on economic sustainability to accentuate improving the automotive SC's financial performance and establishing its soundness in the longterm. In our research, we focus on organizations' ability within the automotive SC to attain high financial performance in the long-term instead of concentrating on short-term goals of improved profitability and productivity. Therefore, this study defines economic supply chain sustainability as the driver of an organization's improved financial performance and the supply chain through systemic and strategic coordination between multiple business functions (Jin et al., 2017). Keeping in view the significant role played by both the customers and suppliers in achieving SCI, the study takes a comprehensive view of the SC and consider that the SSCP is dependent on the ability of the SC partners to adapt to the increasing environment dynamics (Gunasekaran et al., 2017; Vanderhaeghe \& de Treville, 2003). Accordingly, digitalization technological advancements present increasing challenges to modern SC networks in terms of complexity and dynamicity, which requires a higher level of dynamic capabilities (DC) in the SC. Therefore, SSC performance and DC are related through similar environmental and organizational conditions, making the application of DC concepts in the field of SCP a logical choice (Hong et al., 2018; Beske et al., 2014).

Furthermore, organizations striving for a sustainability strategy are increasingly exposed to unpredictable changes than if they do not aim. More powerful players in such environments are more likely to sanction organizations that do not respect their sustainability requirements. The worst thing is when these requirements are changing at a high pace and in unpredictable ways. Therefore, SCP and SSCP address the dynamics incorporated onto organizations through the influences of a globalized world with its characteristics of highly vulnerable logistic networks, globalized competition, and almost instant digitalization and information sharing capabilities (Beske, 2012, Beske et al., 2014; Hong et al., 2018). These factors are characteristics of a highly dynamic environment for which the DC concept is intended.

\subsection{Blockchain technology adoption and sustainable supply chain performance}

The large number of actors involved in a SC network results in a lack of transparency and accountability (Casey \& Wong, 2017). Therefore, as the leading technology developed in the context of digitalization in the SC, BT resulted in safe transactions, improved transparency, and product traceability (Aste et al., 2017; Kshetri, 2018), resulting in reduced costs and improved SSCP (Queiroz and Wamba, 2019). The other benefits of BT include increased accountability and auditability (Kshetri, 2018; Zou et al., 2018), fraud prevention (Lu \& Xu, 2017), privacy, cyber-security, and protection (Kshetri, 2017), and improved financing processes (Ahluwalia et al., 2020). The level of trustworthiness offered by the BT-enabled SC is found to be the essential element in developing closed SC relationships and improved SSCP (Kwon \& Suh, 2005; Panayides \& Lun, 2009). Following this observed potential of BT for improving SSCP, the study proposes the first hypothesis as: 
H1 BTadoption directly and positively influences the SSCP.

\subsection{Blockchain technology adoption, supply chain integration, and sustainable supply chain performance}

BT digitally integrates multiple stakeholders, facilitating supply chains with benefits of product traceability, settlement of transactions, process automation, and execution of smart contracts (Chang et al., 2019; Wang et al., 2018). Polim et al. (2017) identify information integration as one of the significant capabilities of BT. The SCI provided by BT is highly secured and prevents the information stored on the ledger from unauthorized access (Xu et al., 2017). BT enables hyper-levels of SCI that integrate the customers, supplier, and customer's information (Kamble et al., 2018; Korpela et al., 2017). Kshetri (2018) suggest integrating Blockchain with IoT to identify the source of SC disruptions, which can successfully address the crises as product recalls. Similar integration of BT with other emerging technologies will reduce the uncertainty, enhancing SC transparency (Biswas et al., 2017; Lu and Xu 2017), process integration (Lee and Pilkington 2017), and traceability (Jeppsson and Olsson 2017). Blockchain enhances privacy, auditability and increases the operational efficiency of supply chains (Gupta 2017; Weber et al., 2016). The literature suggests that SCI influences SSCP (Huo 2012; Vanpoucke et al., 2017). The recent studies analyzing the effect of ICT-enabled integration technologies such as IoT (De Vass \& Shee, 2018; Rai et al., 2006; Yu et al., 2015) and SC information systems (Sundram et al., 2018) on SSCP, suggests SCI as a significant mediating variable. This leads to the second and third hypothesis as:

H2 BT adoption directly and positively influences SCI.

H3 SCI mediates the relationship between BTA and SSCP.

\section{Research methodology}

\subsection{Procedures and sample}

The proposed model, shown in Fig. 1 and the associated hypothesizes, were tested using a survey-based approach. The companies were first selected from the Automotive Components Manufacturers Association of India (ACMA) and The Society of Indian Automotive Manufacturers (SIAM) database. The online questionnaire was designed and distributed using a Google-drive link to 525 managers from 305 companies. The participation in the survey was kept voluntarily and only those respondents who have at least two years of experience in the automotive industry in order to ensure a minimum of familiarity of the respondents with the specifies of the automotive sector. Additionally, only respondents aware of the BT and SCI concepts were requested to participate in the survey. A total of 253 respondents representing 187 automotive and auto-component manufacturing firms responded to the survey. Overall the response rate was approximately $48 \%$. The respondents of this study varied in terms of gender (Male- $82 \%$, Female-18\%), work experience (2 to 5 years-36\%, 5 to 10 years-39\%, 10-15 years-13\%, above 15 years-12\%), and their position (Production/manufacturing managers 32\%, Digitalization and technology lead 


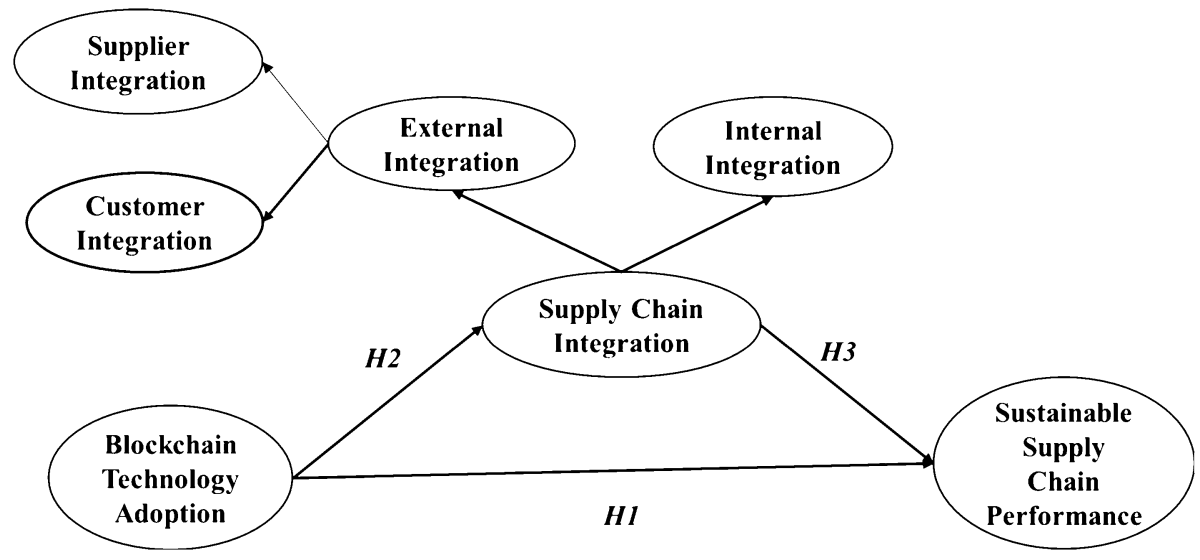

Fig. 1 The proposed research model

managers $12 \%$, Procurement and supply-18\%, Plant managers-8\%, SC planning-21\% and Logistics-9\%).

For analysis, all the statistical analysis was performed on the single value obtained after averaging the multiple responses from a single company for all the items. Therefore, the effective sample size was the number of organizations $(n=187)$ (Venkatraman \& Grant, 1986; Huo et al., 2015). These 187 companies varied on the characteristics of the number of employees (less than 100 employees-17\%, 100-500 employees-33\%, 500-1000 employees-35\%, and above 1000 employees-15\%) and type of ownership (private-78\% and joint ventures-22\%). The sample size of 187 companies was found to be reasonable for conducting confirmatory factor analysis (CFA) and structural equation modeling (SEM) considering the exploring topic of BTA and its relationship with SCI and SSCP (Sideridis et al., 2014; Wolf et al., 2013).

\subsection{Measurement scales}

All the responses were collected on a five-point Likert scale. The BTA measurement items ranged from 1 (not considering implementing it) to 5 (successfully implemented). The items for BT were developed based on the descriptive items listed by Kamble et al. (2018) and Queiroz and Wamba (2019). It included nine items concerning the present status of implementation of the BT (e.g., Our manufacturing firm is in the process of implementing or implemented BT). As the items developed for measuring the BT were new 25 manufacturing practitioners and three academics with the knowledge of BT were approached for pre-testing the BTA dimension scales. The BT scale originally included 12 items, which were subsequently reduced to nine following the advice from the expert panel consulted.

The measures of SCI were adapted from Lu and Xu (2017) and Zhu et al. (2017) and ranged from 1 (highly disagree) to 5 (highly agree). It included seventeen items classified in three primary constructs namely, internal integration, customer integration, and supplier integration. The measurement scale for SSCP was adapted from Green et al. (2008) and has been adopted in many other studies (Gunasekaran et al., 2017; Dwayne Whitten et al., 2012). The items ranged from 1 (strongly disagree) to 5 (highly agree) and included eleven 
measurement items focused on the economic sustainability dimension. The list of measurement items used for the study is presented in Appendix I.

\subsection{Validity analysis}

\subsubsection{Non-response error and common method bias}

The collected data were subjected to a non-response bias test before using it for further statistical analysis. As per the suggestions of Armstrong and Overton (1977), the extrapolation technique was employed to accommodate late responses to non-respondents. The total time taken to complete the survey was ten weeks (28th October 2019 to 10th January 2020), during which two waves of mail were sent. The collected responses were split into two groups. One before the second wave (sample responses =143) and the other after the second wave (sample responses $=110$ ). Two sample t-test was used to test the differences in these two groups' mean values on all the items. The results indicated no significant differences between the two groups, suggesting that the second wave of respondents was not different from the first wave of respondents. The t-values observed for the constructs were: BTA $(\mathrm{t}=-1.420 ; p=0.158), \mathrm{II}(\mathrm{t}=1.591, p=0.114), \mathrm{CI}(\mathrm{t}=-0.415, p=0.679)$, SI $(\mathrm{t}=0.866, p=0.388)$, and SSCP $(\mathrm{t}=0.236, p=0.814)$. Hence, we conclude that there were no non-response bias issues in the data. The common method bias is a common issue in statistical-based investigations when the data is collected from a single respondent from a company. This may lead to an artificial increase in sample sizes and inflated estimates (Podsakoff \& Organ, 1986). The common method bias was reduced by ensuring that the measurement items were kept simple, maintaining the respondent's anonymity, and including only those respondents who are aware of the concepts on BT and SCI (Podsakoff et al., 2003).

Further, we did not restrict the responses to a single respondent in the organization but collected an average of three responses in each company that was later averaged to compute a single response. However, we tested the presence of common method bias statistically, as Podsakoff et al. (2003) recommended using Harman's one-factor test. The complete model with five constructs exhibited a combined total variance of $78 \%$, whereas the first factor accounted for only $44 \%$ of the total variance. The results did not show any presence of common method bias in the data.

\subsubsection{Descriptive statistics and normality of data}

The mean, standard deviation, and normality measures such as Skewness and kurtosis are presented in Table 1. The mean scores for the BTA varied between 2.91 and 3.52, indicating that the automotive manufacturing organizations in India are implementing BT. The mean values for the SCI indicated a satisfactory level of II (3.53-3.82), CI (3.64-3.70), and SI (3.8-4.19) in the organizations. The mean values in the range of 3.88-4.04 indicated the high ability of the organizations to achieve improved SSCP with the implementation of BT. The maximum absolute values for Skewness and Kurtosis were observed to be 1.33 (with a standard error of 0.206) and 2.09 (with a standard error of 0.410 ), respectively. The Skewness and Kurtosis values were within the prescribed limits and indicated the normality of the data (Curran et al., 1996). 
Table 1 Descriptive statistics and factor loadings

\begin{tabular}{|c|c|c|c|c|c|}
\hline Measurement Items & Mean & SD & Skewness & Kurtosis & Factor loadings \\
\hline BT1 & 3.07 & 1.35 & -0.19 & -1.16 & 0.802 \\
\hline BT2 & 3.19 & 1.37 & -0.24 & -1.23 & 0.791 \\
\hline BT3 & 3.52 & 1.41 & -0.51 & -1.04 & 0.649 \\
\hline BT4 & 3.04 & 1.47 & -0.16 & -1.39 & 0.738 \\
\hline BT5 & 3.28 & 1.41 & -0.31 & -1.21 & 0.664 \\
\hline BT6 & 2.91 & 1.43 & 0.06 & -1.27 & 0.801 \\
\hline BT8 & 2.99 & 1.28 & -0.10 & -0.96 & 0.763 \\
\hline ВТ9 & 2.99 & 1.37 & -0.10 & -1.18 & 0.704 \\
\hline BT7 & 3.04 & 1.52 & -0.15 & -1.48 & 0.554 \\
\hline II1 & 3.78 & 1.08 & -0.65 & -0.30 & 0.674 \\
\hline II 2 & 3.53 & 1.11 & -0.32 & -0.58 & 0.846 \\
\hline II3 & 3.90 & 1.03 & -0.90 & 0.71 & 0.602 \\
\hline II4 & 3.76 & 1.11 & -0.65 & -0.34 & 0.676 \\
\hline II5 & 3.54 & 1.09 & -0.26 & -0.63 & 0.836 \\
\hline II6 & 3.82 & 1.01 & -0.95 & 1.00 & 0.595 \\
\hline CI1 & 3.64 & 1.31 & -0.88 & -0.31 & 0.863 \\
\hline $\mathrm{CI} 2$ & 3.70 & 1.30 & -0.88 & -0.29 & 0.871 \\
\hline CI3 & 3.68 & 1.34 & -0.88 & -0.37 & 0.867 \\
\hline CI4 & 3.67 & 1.35 & -0.86 & -0.43 & 0.861 \\
\hline CI5 & 3.70 & 1.16 & -0.77 & 0.05 & 0.790 \\
\hline SI1 & 3.80 & 1.09 & -0.86 & 0.14 & 0.662 \\
\hline $\mathrm{SI} 2$ & 3.92 & 1.09 & -1.16 & 0.94 & 0.655 \\
\hline $\mathrm{SI} 3$ & 4.17 & 0.93 & -1.33 & 2.09 & 0.875 \\
\hline SI4 & 4.03 & 0.97 & -0.93 & 0.79 & 0.791 \\
\hline SI5 & 4.06 & 0.96 & -1.01 & 1.03 & 0.827 \\
\hline SI6 & 4.19 & 0.90 & -1.23 & 1.85 & 0.850 \\
\hline SSCP1 & 4.04 & 1.04 & -1.17 & 1.16 & 0.921 \\
\hline SSCP2 & 4.03 & 1.03 & -1.19 & 1.28 & 0.926 \\
\hline SSCP3 & 4.02 & 1.04 & -1.16 & 1.19 & 0.930 \\
\hline SSCP4 & 3.99 & 1.01 & -1.01 & 0.86 & 0.897 \\
\hline SSCP5 & 4.01 & 0.99 & -1.11 & 1.23 & 0.935 \\
\hline SSCP6 & 3.99 & 1.02 & -1.15 & 1.28 & 0.931 \\
\hline SSCP7 & 3.98 & 1.01 & -1.15 & 1.30 & 0.933 \\
\hline SSCP8 & 3.93 & 1.06 & -0.91 & 0.51 & 0.908 \\
\hline SSCP9 & 4.01 & 0.85 & -1.03 & 1.87 & 0.763 \\
\hline SSCP10 & 3.83 & 1.01 & -0.63 & 0.25 & 0.787 \\
\hline SSCP11 & 3.83 & 1.02 & -0.66 & 0.20 & 0.866 \\
\hline
\end{tabular}

\subsubsection{Factor analysis}

Factor analysis was performed to test how the respondents perceived the multiple items selected for the study. The factor analysis was performed on all the 35 measurement items using principal components and Varimax rotation methods. Five factors were extracted, 
explaining 78\% of the total variance. The "Kaiser-Mayer-Olkin" (KMO) measure of sampling adequacy value was observed to be 0.90 (Barlett's test $p$-value of 0.00 ), which is considered to be an excellent value. The factor loading values are given in Table 1.

\subsubsection{Multicollinearity analysis}

The presence of multicollinearity within the measurement items was verified with the variance inflation factor (VIF) by collapsing all the items into a composite index for testing the structural model (Boßow-Thies \& Albers, 2010). The VIF values ranged between 1.231 and 2.063, below the threshold value of greater than 1 and less than 10 (Hair et al., 2010). The appropriateness of the sample size was ascertained with the power analysis $(1-\beta)$ test (Cohen, 1992). The posthoc test was performed on G*Power 3.1, at a significance level of 0.05 and effect size of 0.10 , resulting in the high magnitude of power 0.9980 , which was above the cut-off value of 0.80 suggested by Cohen (1992).

\section{Results}

\subsection{Measurement model}

The unidimensionality of the theoretical constructs was tested through CFA (Gerbing $\&$ Anderson, 1988). The model fit indices of Chi-square $(\chi 2)=1729.57, \mathrm{df}=619, \chi^{2}$ / $\mathrm{df}=2.794$, RMSEA $=0.061, \mathrm{CFI}=0.887$, and $\mathrm{TLI}=0.896$ ensured a moderate fit (Bentler \& Bonett, 1980; Hu \& Bentler, 1999; Carmines \& McIver, 1983). The convergent validity was tested by referring to the factor loadings obtained from exploratory factor analysis, composite reliability (Nunnally \& Bernstein, 1978; O’Leary-Kelly \& Vokurka, 1998), and average variance extracted (AVE) scores (Fornell \& Larcker, 1981). As observed in Table 1, all the factor loadings for the items were higher than the recommended cut-off value of 0.50 (Hair et al., 2014). The composite reliability and AVE values were also higher than the recommended cut-off of 0.70 and 0.50 , respectively (see Table 2 ). The factor loadings, composite reliability, and the AVE ensured that the selected constructs had no convergent validity issues. The discriminant validity was tested by comparing the correlation between the constructs and the square root of AVE. Table 2 shows that the square root AVE (shown in bold numerical) for each construct was higher than the correlations between that construct and the other constructs, ensuring no discriminant validity issues (Fornell \& Larcker, 1981).

Table 2 Composite reliability, AVE, and correlations between the constructs

\begin{tabular}{llllllll}
\hline Constructs & CR & AVE & SSCP & CI & II & SI & BT \\
\hline SSCP & 0.985 & 0.860 & $\mathbf{0 . 9 2 7}$ & & & & \\
CI & 0.985 & 0.928 & 0.395 & $\mathbf{0 . 9 6 4}$ & & & \\
II & 0.879 & 0.558 & 0.481 & 0.610 & $\mathbf{0 . 7 4 7}$ & & \\
SI & 0.947 & 0.752 & 0.481 & 0.577 & 0.629 & $\mathbf{0 . 8 6 7}$ & \\
BT & 0.908 & 0.525 & 0.334 & 0.558 & 0.403 & 0.344 & $\mathbf{0 . 7 2 5}$ \\
\hline
\end{tabular}

$C R$ Composite reliability, AVE Average variance extracted, SSCP Sustainable Supply chain performance, $C I$ Customer integration, II Internal integration, SI Supplier integration, BT Blockchain technology 


\subsection{Hypothesis testing}

The SEM was used to analyze the structural model and test the hypothesis developed in the study. Using SPSS software, the standardized beta coefficients $(\beta)$ and multiple correlation coefficients $\left(\mathrm{R}^{2}\right)$ for the model's constructs are depicted in Fig. 2. The structural model shown in Fig. 2 represents BT's combined and indirect effect on SSCP through the mediating effect of SCI. It is noteworthy that financial performance is considered as the only driver for economical supply chain sustainability. The model exhibited the following modification indices: $\chi^{2}=12.654, \chi^{2} / \mathrm{df}$ ratio $=$ goodness of fit index $(\mathrm{GFI})=0.95$, adjusted goodness of fit index $(\mathrm{AGFI})=0.84$, non-normated fit index $(\mathrm{NFI})=0.93$, comparative fit index $(\mathrm{CFI})=0.94$ and root mean square residual $(\mathrm{RMR})=0.05$, indicating a satisfactory model fit (Bentler \& Bonett, 1980; Carmines \& McIver, 1983; Hu \& Bentler, 1999).

\subsubsection{Direct effects of BTA on $\mathrm{SCl}$ and $\mathrm{SSCP}(\mathrm{H} 1$ and $\mathrm{H} 2)$}

The direct effects of BT on the SSCP (H1) and SCI (H2) were analyzed using SEM analysis. The hypothesis H1, stating that the BT directly and positively affects the SSCP was found to be significant $(\beta=0.192, p=0.002)$ with the BT explaining of $6.5 \%\left(\mathrm{R}^{2}\right)$ of the variance in the dependent variable SSCP. The hypothesis $\mathrm{H} 2$, stating that BTA directly and positively affects the SCI, was also significant $(\beta=0.329, p=0.000)$, with the BTA explaining $30.8 \%\left(\mathrm{R}^{2}\right)$ of the variance in the dependent variable SCI. The $\mathrm{R}^{2}$ coefficient values, being relatively low, indicate that exogenous variables may intervene in our dependent variables. However, this does not alter the fit of our model.

\subsubsection{Mediating effect of $\mathrm{SCl}$ on $\mathrm{BTA}$ and SSCP $(\mathrm{H} 3)$}

The values obtained from the analysis of the integrated research model in Fig. 2 were used to analyze SCI's mediating effect on the relationship between BTA and SSCP. Hoyle and Kenny (1999) identified three conditions of mediation as full mediation, partial mediation, and no mediation. Full mediation exists when the direct effect of the independent variable on the dependent variable in the presence of the mediating variable is insignificant, and the

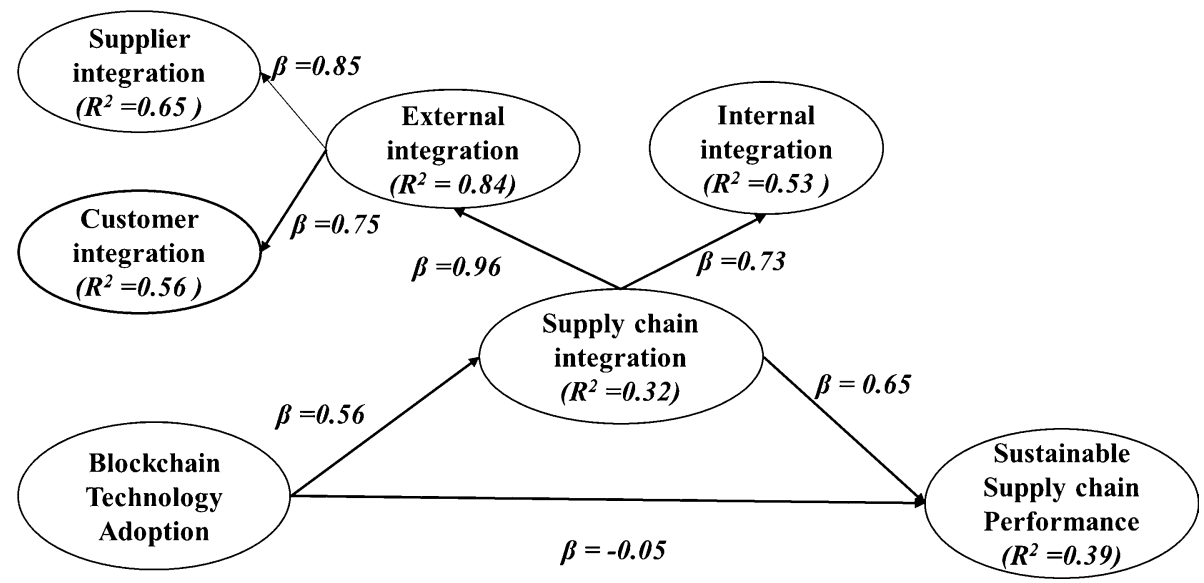

Fig. 2 Integrated structural equation model 
direct effect of the independent variable on the dependent variable without mediating variable is significant. The direct effects of the BTA with and without the mediating variable on the SSCP are given in Table 3. The result indicates a significant presence of SCI with a full mediation effect on the relationship between the BTA and SSCP. The significance of this effect was tested using the Sobel test (Sobel, 1982). The result indicates that the mediation effect is significant with a Z-statistic of 3.96, a standard error of 0.80 , and a path coefficient of $\beta=0.364(p<0.0001)$. The summary of the results for the hypothesis tested in the study is presented in Table 4.

The results of the study support the hypothesis stating that BTA directly and positively influences the SSCP. This finding complements the previous studies claiming that ICT enabled SCI initiatives to positively influence the SSCP (Zhou et al., 2015; Dedrick et al., 2003; Kauppi, 2013; Kim \& Park 2013; Qrunfleh \& Tarafdar 2014; Vanpoucke et al., 2017). Further, the hypothesis stating that BTA directly and positively influences the SCI supports a similar claim made by previous researchers on the use of new technologies for integrating supply chains (Xu et al., 2017; Korpela et al., 2017; Kshetri 2018; Biswas et al., 2017; Lu \& Xu, 2017). The results recognize SCI's role as a significant mediating variable between the BTA and SSCP, validating the previous studies assessing ICT-enabled integration technologies on SSCP (De Vass \& Shee, 2018; Rai et al., 2006; Yu et al., 2015; Sundram et al., 2018). In the fully mediated model, BTA and SCI explained $39 \%$ of the variance in SSCP

\section{Study implications}

Below are the main implications of this study for theory and practice.

\subsection{Theoretical implications}

Applying dynamic capabilities theory, the study provided understanding into the relationship between BTA, SCI, and SSCP. The findings suggest that the disruptions caused by the digitization of supply chains can be addressed by adopting BT, which influences the SSCP through the SCI improvements. Following empirical analysis, it is found that BT is a significant dynamic capability of the organization that can integrate, builds and reconfigure, both the internal and external competencies to address the challenges posed by the rapidly changing environment (Saberi et al., 2019).

Our results also highlight the fact that stakeholders' integration in the SC matter. The development and/or improvement of suppliers and customers integration in the SC can help organizations while implementing BT in their pursuit of SSCP (De Vass \& Shee, 2018; Yu et al., 2015). This finding accords with previous research on SSCP. Indeed, the more stakeholders and partners in the SC an organization can integrate in its sustainability strategy, the more it may benefit from BT technology to enhance its partnership and SC integrity. Openness, transparency, neutrality, reliability, and security for all supply chain agents and stakeholders can exist in this technological context (Bai \& Sarkis, 2020; Kamble et al., 2020). Besides, as an organization becomes more capable of accomplishing these goals, it may also become more dynamic and responsive to the environmental changes related to its SC. BT enables organizations to new offerings in a shorter period and reorganizes sustainable supply chains according to 


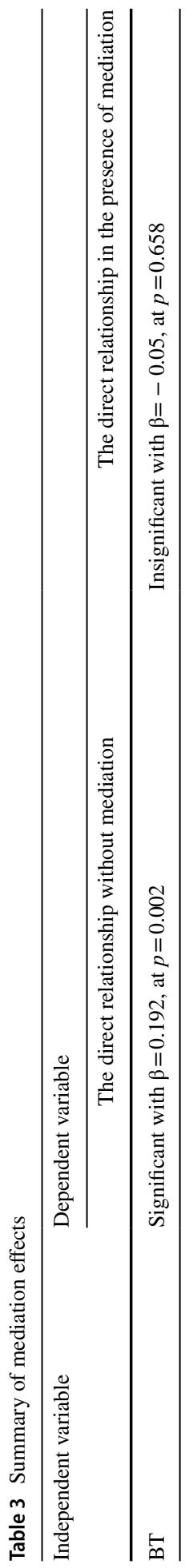


Table 4 Summary of the hypothesis tested in the study

\begin{tabular}{llllll}
\hline Hypotheses & $\begin{array}{l}\text { Unstand- } \\
\text { ardized } \\
\text { estimate }\end{array}$ & S.E. & C.R. & Sig. & Result \\
\hline $\begin{array}{l}\text { H1: BTA directly and positively influences the } \\
\text { SSCP }\end{array}$ & 0.192 & 0.063 & 3.036 & 0.002 & Supported \\
H2: BTA directly and positively influences SCI & 0.329 & 0.084 & 3.938 & 0.000 & Supported \\
H3: SCI mediates the relationship between & $0.364^{*}$ & - & & & Full mediation exists \\
BTA and SSCP & & & & & \\
\hline
\end{tabular}

*Standardized coefficient based on the values obtained in Fig. 2

changes in stakeholder's demand (Bai \& Sarkis, 2020). This is particularly true since BT can support faster data collection, storage, and management, supporting significant product and supply chain information (Saberi et al., 2019).

Economically, implementing BT can favor organizations and their SSCP from various levels influencing their economic performance. Indeed, waste and cost reduction may result in enhanced green performance, such as reduced raw material consumption and energy efficiency (Belhadi et al., 2018). Additionally, blockchains may give rise to supply chain disintermediation where fewer partners lead to transaction costs and time reduction, decreasing business waste in the supply chain (Saberi et al., 2019). Besides, BT can communicate all changes of the data on the spot, enabling for potentially fast deployment of products and processes while reducing human errors and transaction times (Bai \& Sarkis, 2020; Di Vaio \& Varriale, 2020). Moreover, BT can guarantee the data's security and authenticity, which will reduce the cost of hindering data from willful and fickle infringement, increasing supply chain risks and reducing business reliability (De Vass \& Shee, 2018). Besides, customers and government now ask for transparency within the supply chain. Pioneering companies realized the competitive advantage of transparency (Saberi et al., 2019), increasing customers' trust to purchase more and benefit the firm financially (Bai \& Sarkis, 2020; Saberi et al., 2019).

Thus, the study contributes to theory by providing empirical evidence on BT's impact on the SSCP. The findings addressed the gap and argued that BT is positively influencing SSCP under SCI's mediating effect. The results also extend the literature on ICT-enabled technologies, i.e., BT, SCI, and SSCP (Saberi et al., 2019) by proposing a moderated multi-mediation model helpful in understanding the complex dynamics and interrelationships in this context. Hence, BT is related to supply chain integration and sustainable supply chain performance (Bai \& Sarkis, 2020). Our study also contributes to the extant body of knowledge about the external and internal factors of supply chain integration that prevent or promote the successful adoption of BT with the aim of SSCP by highlighting the effect of different dimensions of SCI, namely, process integration (PI), supplier integration (SI), and customer integration (CI).

Finally, the research is of extreme value since it focuses on BT outcomes, specifically in the automotive sector, which is less considered in the literature. In such an industry, the process becomes much digitalized; hence, automotive companies may benefit the most from BT adoption. 


\subsection{Managerial implications}

The study shows that the practitioners in the automotive industries perceive that the BT-enabled SCI enhances the SSCP based on the financial component as a driver of supply chains' economic sustainability. Our findings support the fact that blockchain is believed to be a disruptive force in the automobile industry, with most industry practitioners prepared to invest in this technology (FRPT, 2018). The BT in the automobile sector can strengthen the trust and collaboration between the business partners, including the customers and the vehicles (Schifanella et al., 2021).

The BT is found to have a direct effect on all three dimensions of SCI. This implies that BT as a dynamic capability is perceived to improve both the external (suppliers and customers) competencies and internal integration. SC managers can utilize these insights to enhance their SC network efficiency with the adoption of BT. The blockchain-enabled SC uses shared, secured, decentralized ledgers, and autonomous smart contracts, reducing intermediaries' role in the SC networks, thus making the supply chain more secure and reliable. Our results support the automobile industry's various initiatives in developing an eco-system built on trust and partnership. Chen et al. (2020) advocate BT's use in resolving the disputes that occur in the used car transactions due to lack of transparency in transactions. They propose BT to upload the vehicle information by the owners, regulatory authorities, workshop mechanics, insurance agencies, and other automobile eco-system stakeholders, benefitting the used car transactions. The BT in the automobile industry supports symmetric information enhancing trust. BT for the reduction in fraud related to automobile odometers (Abbade et al., 2020) proposes. The proposed framework adopts an efficient consensus algorithm based on proof of work. Baza et al. (2019) proposed a distributed firmware update scheme for intelligent vehicles based on Blockchain and smart contract technology. They used a consortium blockchain involving different manufacturers to ensure the authenticity and integrity of firmware updates. A reward system is built is established to incentivize the vehicles to distribute the updates that maintains a credit reputation for each distributor account in the Blockchain.

These features provide the organizations with error-free and immutable information accessible to all the authorized partners providing a high level of integration. It is implied that one of the critical reason for SCI to be a significant mediating variable is the increased level of data security provided by the BT, which restricts the SC members to provide false information, replace or make any changes in the existing information increasing the level of trust and confidence in the SC transactions (Paliwal et al., 2020). The finding implies that the blockchain capabilities improved supplier integration, strengthening the SCI, resulting in improved relationships with the suppliers, quality products, and quick deliveries.

BT has massive potential for internet-enabled vehicles or self-driving cars. The intelligent vehicles will be exposed to an insecure environment and several vulnerabilities. Trustworthiness, accuracy, and security of received and broadcasted data would be of high significance in such settings, wherein BT can be used to build a reliable peer-topeer network. Further, Singh and Kim (2018) proposed a BT-enabled intelligent vehicle communication framework. The performance of this framework was validated with emphasis on real-time traffic scenarios. The above developments in the automobile industry support our findings on BT's role in enhancing the external supply chain integration and developing a partner eco-system based on trust and reliability dimensions.

Similarly, it enhances the relational trust with the customers by providing them with access to the products' historical information. The customers can trace the product to 
its origin, which is not possible in the traditional supply chains. The benefits of blockchain-enabled SCI are implied to be grounded in mutual trust and commitment and can provide optimized benefits to the organizations. Specifically, given that the automotive supply chains extend over different industries, countries, and are governed by other regulatory boundaries, BT for data sharing is believed to be a highly efficient way to manage reference data. It is implied that BT will reduce data errors and provide real-time access to critical data across the supply chain partners, ensuring natural workflows and availability of tampered proof authentic data. Likewise, in terms of traceability across the supply chain, BT enables the automotive industry to go one step forward towards a new era of end-to-end transparency in the global supply chain system where customers and suppliers can share any information with increased confidence in a trusted network.

The study results are highly beneficial to the practitioners who are in the transition of implementing BT in their organizations. In India, BT is a relatively new concept, and our findings will encourage automotive industry practitioners to invest in BT and enhance their SC sustainability.

\section{Conclusions}

The study aimed to assess the relationship between BT, SCI, and SSCP. Responses collected from 138 Indian automotive companies were analyzed following confirmatory factor analysis and structural equation modeling. Underpinning the study on dynamic capabilities theory, BT is found to impact the organizational resources and supply chain performance. The study supports the previous literature on ICT-enabled SCs, acknowledging BT's decisive role in affecting the SSCP through the mediation of supply chain integration.

Like any other research study, our study outlines some limitations that pave the way for future research directions. Since the study is based on limited data collected from a specific sector, it is difficult to generalize the findings. The study is based on managers' perceptions in the Indian automotive industry; thus, the results may not align with other countries or sectors. The results are likely to be different for under-developed countries with limited organizational capability and ICT resources availability. Although care was taken to approach only respondents who were familiar with BT's concept, the level of understanding is expected to vary and thus the perceived benefits of BT for SSCP.

Further, the current study considers mainly the economic component of SSCP. However, future studies are recommended to put more focus on environmental and social SSCP. Besides, BT applications are typically integrated with other emerging technologies from Industry 4.0, such as big data analytics, IoT, and additive manufacturing. The present study did not consider any specific technology integration with BT. Therefore, future studies can consider such integration to draw far-reaching implications.

\section{Appendix: Details of measurement items}

\section{Blockchain technology adoption}

Please evaluate the blockchain applications your company is in the process of implementing or implemented using the measurement scales provided below: 
$1=$ not considering it; $2=$ planning to consider it, which means in the early phases of discussion and consideration which may not be considered for final implementations; $3=$ considering it currently, which means that it has been planned for and is due to be implemented but not carried out yet; $4=$ being implemented; $5=$ implementing successfully.

BT1 Smart contracts for automatically implementing multiparty agreements.

BT2 Order validation and approval.

BT3 Invoice processing and final payment settlement.

BT4 Verification of conflict-free raw material.

BT5 Validating the manufacturing parameters.

BT6 Leveraging the scale of big data availability.

BT7 Standardized quality documentation.

BT8 Integrating the manufacturing practices.

BT9 Logistics asset management (such as machines, transport vehicles, warehouses, material handling equipment's etc.)

\section{Supply chain integration}

Please indicate how the following statements apply to your supply chain in the past three years (5-point scale: strongly disagree - strongly agree).

\section{Supplier Integration}

SI1 Established strategic partnerships with our key suppliers.

SI2 Include key suppliers in planning and goal-setting activities.

SI3 Create an environment of trust and benefit with our suppliers.

SI4 Use information technologies to share real-time information with our key suppliers.

SI5 Seek guidance and involve our key suppliers in joint problem solving.

SI6 Involve suppliers in product design and development.

\section{Customer integration}

CI1 Established strategic partnership with our key customers.

CI2 Involve our key customers in improving inter-organizational processes.

CI3 Create an environment of trust and benefit with our customers.

CI4 Use information technologies to strengthen the linkages with customers.

CI5 Involve customers in product design and development.

\section{Internal Integration}

II1 All the internal functions in my organization have data integration and are in synchronization with each other.

II2 We use enterprise resource planning applications for integrating the different functions II3: Integrative inventory management. 
II4 All the supply chain functions namely: planning, sourcing, production, delivery and sales have real-time integration.

II5 We have regular inter-departmental meetings for identification and solving internal issues.

II6 The product design team has representation from different cross-functional departments.

\section{Sustainable Supply chain performance (SSCP).}

Please indicate the extent to which you agree or disagree with each statement as the statement relates to your organization's primary supply chain (5-point scale: strongly disagree - strongly agree).

SSCP1 This organization's primary supply chain has the ability to deliver zero-defect products to final customers.

SSCP2 This organization's primary supply chain has the ability to deliver value-added services to final customers.

SSCP3 This organization's primary supply chain has the ability to eliminate late, damaged and incomplete orders to final customers.

SSCP4 This organization's primary supply chain has the ability to quickly respond to and solve problems of the final customers.

SSCP5 This organization's primary supply chain has the ability to deliver products precisely on-time to final customers.

SSCP6 This organization's primary supply chain has the ability to deliver precise quantities to final customers.

SSCP7 This organization's primary supply chain has the ability to deliver shipments of variable size on a frequent basis to final customers.

SSCP8 This organization's primary supply chain has the ability to deliver small lot sizes and shipping case sizes to final customers.

SSCP9 This organization's primary supply chain has the ability to minimize total product cost to final customers.

SSCP10 This organization's primary supply chain has the ability to minimize all types of waste throughout the supply chain.

SSCP11 This organization's primary supply chain has the ability to minimize channel safety stock throughout the supply chain.

Acknowledgements The third author would like to especially thank the UK Research and Innovation funding service for awarding the project "REMP: Remanufacturing e-marketplace for circular digital supply chain" under the competition Innovate UK- Manufacturing made smarter: digital supply chain, feasibility studies.

Open Access This article is licensed under a Creative Commons Attribution 4.0 International License, which permits use, sharing, adaptation, distribution and reproduction in any medium or format, as long as you give appropriate credit to the original author(s) and the source, provide a link to the Creative Commons licence, and indicate if changes were made. The images or other third party material in this article are included in the article's Creative Commons licence, unless indicated otherwise in a credit line to the material. If material is not included in the article's Creative Commons licence and your intended use is not 
permitted by statutory regulation or exceeds the permitted use, you will need to obtain permission directly from the copyright holder. To view a copy of this licence, visit http://creativecommons.org/licenses/by/4.0/.

\section{References}

Abbade, L. R., Ribeiro, F. M., da Silva, M. H., Morais, A. F., de Morais, E. S., Lopes, E. M., Alberti, A. M., \& Rodrigues, J. J. (2020). Blockchain applied to vehicular odometers. IEEE Network, 34(1), 62-68.

Ahluwalia, S., Mahto, R. V., \& Guerrero, M. (2020). Blockchain technology and startup financing: A transaction cost economics perspective. Technological Forecasting and Social Change, 151, 119854.

Alfalla-Luque, R., Medina-Lopez, C., \& Dey, P. K. (2013). Supply chain integration framework using literature review. Production Planning and Control, 24(8-9), 800-817.

Anderson, J. C., \& Gerbing, D. W. (1988). Structural equation modeling in practice: A review and recommended two-step approach. Psychological Bulletin, 103(3), 411.

Angelis, J., \& da Silva, E. R. (2018). Blockchain adoption: A value driver perspective. Business Horizons.

Armstrong, J. S., \& Overton, T. S. (1977). Estimating nonresponse bias in mail surveys. Journal of Marketing Research, 14(3), 396-402.

Aste, T., Tasca, P., \& Di Matteo, T. (2017). Blockchain technologies: The foreseeable impact on society and industry. computer, 50(9), 18-28.

Ataseven, C., \& Nair, A. (2017). Assessment of supply chain integration and performance relationships: A meta-analytic investigation of the literature. International Journal of Production Economics, 185, $252-265$.

Bai, C., \& Sarkis, J. (2020). A supply chain transparency and sustainability technology appraisal model for blockchain technology. International Journal of Production Research, 58(7), 2142-2162.

Barreto, I. (2010). Dynamic capabilities: A review of past research and an agenda for the future. Journal of Management, 36(1), 256-280.

Baza, M., Nabil, M., Lasla, N., Fidan, K., Mahmoud, M., \& Abdallah, M. (2019). Blockchain-based firmware update scheme tailored for autonomous vehicles. In 2019 IEEE wireless communications and networking conference (WCNC) (pp. 1-7). IEEE.

Belhadi, A., Touriki, F. E., \& Fezazi, E. S. (2018). Benefits of adopting lean production on green performance of SMEs: A case study. Production Planning \& Control, 29(11), 873-894.

Belhadi, A., Kamble, S. S., Zkik, K., Cherrafi, A., \& Touriki, F. E. (2020). The integrated effect of Big Data Analytics, Lean Six Sigma and Green Manufacturing on the environmental performance of manufacturing companies: The case of North Africa. Journal of Cleaner Production, 252, 119903. https:// doi.org/10.1016/j.jclepro.2019.119903.

Belhadi, A., Zkik, K., Cherrafi, A., \& Sha'ri, M. Y. (2019). Understanding big data analytics for manufacturing processes: Insights from literature review and multiple case studies. Computers and Industrial Engineering, 137, 106099. https://doi.org/10.1016/j.cie.2019.106099

Bentler, P. M., \& Bonett, D. G. (1980). Significance tests and goodness of fit in the analysis of covariance structures. Psychological Bulletin, 88(3), 588.

Beske, P. (2012). Dynamic capabilities and sustainable supply chain management. International Journal of Physical Distribution and Logistics Management, 42(4), 372-387.

Beske, P., Land, A., \& Seuring, S. (2014). Sustainable supply chain management practices and dynamic capabilities in the food industry: A critical analysis of the literature. International Journal of Production Economics, 152, 131-143.

Biswas, K., Muthukkumarasamy, V., \& Tan, W. L. (2017). Blockchain based wine supply chain traceability system. In Future Technologies Conference (FTC) 2017. Vancouver, Canada 29-30 Nov 2017, pp. 56-62. United Kingdom: The Science and Information Organization.

Boßow-Thies, S., \& Albers, S. (2010). Application of PLS in marketing: Content strategies on the internet. In Handbook of Partial Least Squares (pp. 589-604). Berlin: Springer.

Carmines, E. G., \& McIver, J. P. (1983). An introduction to the analysis of models with unobserved variables. Political Methodology, 9(1), 51-102.

Carrera, A. R., \& Kurnia, S. Exploring the roles of ICT supporting sustainability practices. In Proceedings of the Australasian conference on inforamation systems, Adelaide, Australia, 30 November-4 December 2015.

Carter, C. R., \& Rogers, D. S. (2008). A framework of sustainable supply chain management: Moving toward new theory. International Journal of Physical Distribution \& Logistics, 38, 360-387. 
Casey, M., \& Wong, P. (2017). Global supply chains are about to get better, thanks to Blockchain. Harvard Business Review, 13.

Centobelli, P., Cerchione, R., \& Esposito, E. (2020). Pursuing supply chain sustainable development goals through the adoption of green practices and enabling technologies: A cross-country analysis of LSPs. Technology Forecasting and Social Change. https://doi.org/10.1016/j.techfore.2020.119920.

Chang, S. E., Chen, Y. C., \& Lu, M. F. (2019). Supply chain re-engineering using blockchain technology: A case of smart contract-based tracking process. Technological Forecasting and Social Change, 144, $1-11$.

Chen, R. Y. (2018). A traceability chain algorithm for artificial neural networks using T-S fuzzy cognitive maps in Blockchain. Future Generation Computer Systems, 80, 198-210.

Chen, J., Ruan, Y., Guo, L., Lu, H. (2020). BCVehis: A blockchain-based service prototype of vehicle history tracking for used-car trades in China. IEEE Access, 8, 214842-214851. https://doi.org/10.1109/ ACCESS.2020.3040229.

Cohen, J. (1992). A power primer. Psychological Bulletin, 112(1), 155.

Curran, P. J., West, S. G., \& Finch, J. F. (1996). The robustness of test statistics to nonnormality and specification error in confirmatory factor analysis. Psychological Methods, 1(1), 16.

De Vass, T., \& Shee, H. (2018). The effect of "Internet of Things" on supply chain integration and performance: An organisational capability perspective. Australasian Journal of Information Systems, $2,2$.

Dedrick, J., Gurbaxani, V., \& Kraemer, K. L. (2003). Information technology and economic performance: A critical review of the empirical evidence. ACM Computing Surveys (CSUR), 35(1), 1-28.

Dickson, B. (2016). Blockchain has the potential to revolutionize the supply chain. Aol Tech.

Di Vaio, A., \& Varriale, L. (2020). Blockchain technology in supply chain management for sustainable performance: Evidence from the airport industry. International Journal of Information Management, 52, 102014.

Dong, Y., Carter, C. R., \& Dresner, M. E. (2001). JIT purchasing and performance: An exploratory analysis of buyer and supplier perspectives. Journal of Operations Management, 19(4), 471-483.

Dwayne Whitten, G., Green, K. W. Jr., \& Zelbst, P. J. (2012). Triple-A supply chain performance. International Journal of Operations and Production Management, 32(1), 28-48.

Economic Times. (2020), Indian auto industry status report 2020, https://auto.economictimes.india times.com/e/report2020

Eisenhardt, K. M., \& Martin, J. A. (2000). Dynamic capabilities: What are they? Strategic Management Journal, 21(10-11), 1105-1121.

FRPT. (2018). Industry executives see Blockchain becoming disruptive force in auto sector: Study. FRPT- Automobile Snapshot. Accessed February 11, 2021. Available at: https://search.ebscohost. com/login.aspx ?direct $=$ true $\& d b=$ bth $\& A N=133814423 \&$ lang $=$ en $\&$ site $=$ eds-live $\&$ scope $=$ site.

FRPT. (2020a). Require Long-term Regulatory Roadmap to Increase Automobile Sector Contribution To GDP: NRI India. (2020). FRPT- Automobile Snapshot, 22-23.

FRPT. (2020b). Improved vehicle legislation, industry compliances driving connected car market in India: EY. FRPT- Automobile Snapshot. September 2020: 22. Accessed February 11, 2021. https://search.ebscohost.com/login.aspx?direct=true \&db=bth\&AN=147576765\&lang=en\&site= eds-live\&scope $=$ site

Flynn, B. B., Huo, B., \& Zhao, X. (2010). The impact of supply chain integration on performance: A contingency and configuration approach. Journal of Operations Management, 28(1), 58-71.

Formentini, M., \& Taticchi, P. (2016). Corporate sustainability approaches and governance mechanisms in sustainable supply chain management. Journal of Cleaner Production, 112, 1920-1933.

Fornell, C., \& Larcker, D. F. (1981). Evaluating structural equation models with unobservable variables and measurement error. Journal of marketing research, 18(1), 39-50.

Gawankar, S. A., Kamble, S., \& Raut, R. (2017). An investigation of the relationship between supply chain management practices (SCMP) on supply chain performance measurement (SCPM) of Indian retail chain using SEM. Benchmarking: An International Journal, 24(1), 257-295.

Green, K. W. Jr., Whitten, D., \& Inman, R. A. (2008). The impact of logistics performance on organizational performance in a supply chain context. Supply Chain Management: An International Journal, 13(4), 317-327.

Gunasekaran, A., Papadopoulos, T., Dubey, R., Wamba, S. F., Childe, S. J., Hazen, B., \& Akter, S. (2017). Big data and predictive analytics for supply chain and organizational performance. Journal of Business Research, 70, 308-317.

Gupta, W. (2017). Blockchain for dummies. IBM Limited Edition. USA.

Hair, J., Black, W. C., Babin, B. J., \& Anderson, R. E. (2010). Multivariate data analysis (7th ed.). Pearson Education International. 
Hair, J., Black, W., Babin, B. Y. A., Anderson, R., \& Tatham, R. (2014). Multivariate data analysis. A global perspective. Pearson Prentice Hall.

Helfat, C. E., \& Winter, S. G. (2011). Untangling dynamic and operational capabilities: Strategy for the (N) ever-changing world. Strategic Management Journal, 32(11), 1243-1250.

Hofmann, E., Strewe, U. M., \& Bosia, N. (2018). Discussion-how does the full potential of blockchain technology in supply chain finance look like? In Supply Chain Finance and Blockchain Technology (pp. 77-87). Springer.

Holland, M., Nigischer, C., \& Stjepandić, J. (2017). Copyright protection in additive manufacturing with blockchain approach. Transdisciplinary Engineering: A Paradigm Shift, IOS Press, Amsterdam, 914-921.

Hong, J., Zhang, Y., \& Ding, M. (2018). Sustainable supply chain management practices, supply chain dynamic capabilities, and enterprise performance. Journal of Cleaner Production, 172, 3508-3519.

Hoyle, R. H., \& Kenny, D. A. (1999). Statistical power and tests of mediation. In R. H. Hoyle (Ed.), Statistical strategies for small sample research. Newbury Park: Sage.

Hu, L. T., \& Bentler, P. M. (1999). Cutoff criteria for fit indexes in covariance structure analysis: Conventional criteria versus new alternatives. Structural Equation Modeling: A Multidisciplinary Journal, $6(1), 1-55$.

Huo, B. (2012). The impact of supply chain integration on company performance: An organizational capability perspective. Supply Chain Management: An International Journal, 17(6), 596-610.

Huo, B., Han, Z., Chen, H., \& Zhao, X. (2015). The effect of high-involvement human resource management practices on supply chain integration. International Journal of Physical Distribution and Logistics Management, 45(8), 716-746.

IBEF. (2018). Indian Automobile Industry Analysis, India Brand Equity Foundation (IBEF) 1-27. Available at: https://www.ibef.org, Accessed on 12th December 2018.

IBM. (2020). Can Blockchain be next big disruption for Indian auto sector?. Accessed on March 18, 2021. Available at: https://auto.economictimes.indiatimes.com/news/auto-technology/can-blockchain-benext-big-disruption-for-indian-auto-sector/75419241

Ivanov, D., Dolgui, A., \& Sokolov, B. (2018). The impact of digital technology and Industry 4.0 on the ripple effect and supply chain risk analytics. International Journal of Production Research, 1-18.

Jeppsson, A., \& Olsson, O. (2017). Blockchains as a solution for traceability and transparency. Available at: http://lup.lub.lu.se/student-papers/record/8919957. Accessed on January 5, 2019.

Jeschke, S., Brecher, C., Meisen, T., Özdemir, D., \& Eschert, T. (2017). Industrial internet of things and cyber manufacturing systems. In Industrial Internet of Things (pp. 3-19). Cham: Springer.

Jin, S. H., Jeong, S. J., \& Kim, K. S. (2017). A linkage model of supply chain operation and financial performance for economic sustainability of firm. Sustainability, 9(1), 139

Joshi, D. (2017). IBM, Amazon and Microsoft are offering their blockchain technology as a service. Business Insider, 24.

Kamble, S. S., Gunasekaran, A., Kumar, V., Belhadi, A., \& Foropon, C. (2020). A machine learning based approach for predicting blockchain adoption in supply Chain. Technological Forecasting and Social Change, 163, 120465.

Kamble, S., Gunasekaran, A., \& Arha, H. (2018). Understanding the Blockchain technology adoption in supply chains-Indian context. International Journal of Production Research, 57(7), 2009-2033.

Kano, Y., \& Nakajima, T. (2018). A novel approach to solve a mining work centralization problem in blockchain technologies. International Journal of Pervasive Computing and Communications, 14(1), 15-32.

Kauppi, K. (2013). Extending the use of institutional theory in operations and supply chain management research: Review and research suggestions. International Journal of Operations and Production Management, 33(10), 1318-1345.

Kim, S., \& Park, H. (2013). Effects of various characteristics of social commerce (s-commerce) on consumers' trust and trust performance. International Journal of Information Management, 33(2), 318-332.

Korpela, K., Hallikas, J., \& Dahlberg, T. (2017). Digital supply chain transformation toward blockchain integration. In Proceedings of the 50th Hawaii international conference on system sciences.

Kshetri, N. (2017). Can blockchain technology help poor people around the world?. Conversation. Available at:https://theconversation.com/can-blockchain-technology-help-poor-people-around-the-world76059. Accessed 6 January 2019.

Kshetri, N. (2018). 1 Blockchain's roles in meeting key supply chain management objectives. International Journal of Information Management, 39, 80-89.

Kwon, I. W. G., \& Suh, T. (2005). Trust, commitment and relationships in supply chain management: a path analysis. Supply chain management: an international journal, 10(1), 26-33. 
Lee, H. L., Padmanabhan, V., \& Whang, S. (1997). Information distortion in a supply chain: The bullwhip effect. Management Science, 43(4), 546-558.

Lee, J. H., \& Pilkington, M. (2017). How the blockchain revolution will reshape the consumer electronics industry [Future Directions]. IEEE Consumer Electronics Magazine, 6(3), 19-23.

Lee, J. Y., Yoon, J. S., \& Kim, B. H. (2017). A big data analytics platform for smart factories in small and medium-sized manufacturing enterprises: An empirical case study of a die casting factory. International Journal of Precision Engineering and Manufacturing, 18(10), 1353-1361.

Liu, Y., \& Xu, X. (2017). Industry 4.0 and cloud manufacturing: A comparative analysis. Journal of Manufacturing Science and Engineering, 139(3), 1-8.

Lu, Q., \& Xu, X. (2017). Adaptable blockchain-based systems: A case study for product traceability. IEEE Software, 34(6), 21-27.

Mackelprang, A. W., Robinson, J. L., Bernardes, E., \& Webb, G. S. (2014). The relationship between strategic supply chain integration and performance: A meta-analytic evaluation and implications for supply chain management research. Journal of Business Logistics, 35(1), 71-96.

Mougayar, W. (2016). The business blockchain: Promise, practice, and application of the next internet technology. Wiley.

Mueller, E., Chen, X. L., \& Riedel, R. (2017). Challenges and requirements for the application of industry 4.0: a special insight with the usage of cyber-physical system. Chinese Journal of Mechanical Engineering, 30(5), 1050-1057.

Nassar, S., Kandil, T., Kara, M. E., \& Ghadge, A. (2019). Automotive recall risk: Impact of buyer-supplier relationship on supply chain social sustainability. International Journal of Productivity and Performance Management, (69)3, 467-487.

Nayak, G., \& Dhaigude, A. S. (2019). A conceptual model of sustainable supply chain management in small and medium enterprises using blockchain technology. Cogent Economics \& Finance, 7(1), 1667184.

Nunnally, J. C., \& Bernstein, I. H. (1978). Psychometric Theory. McGraw-Hill .

Näslund, D., \& Hulthen, H. (2012). Supply chain management integration: A critical analysis. Benchmarking: An International Journal, 19(4/5), 481-501.

O’Leary-Kelly, S. W., \& Vokurka, R. J. (1998). The empirical assessment of construct validity. Journal of Operations Management, 16(4), 387-405.

Paliwal, V., Chandra, S., \& Sharma, S. (2020). Blockchain technology for sustainable supply chain management: A systematic literature review and a classification framework. Sustainability, 12(18), 7638.

Panayides, P. M., \& Lun, Y. V. (2009). The impact of trust on innovativeness and supply chain performance. International Journal of Production Economics, 122(1), 35-46.

Pazaitis, A., De Filippi, P., \& Kostakis, V. (2017). Blockchain and value systems in the sharing economy: The illustrative case of Backfeed. Technological Forecasting and Social Change, 125, 105-115.

Pereira, J., Tavalaei, M. M., \& Ozalp, H. (2019). Blockchain-based platforms: Decentralized infrastructures and its boundary conditions. Technological Forecasting and Social Change, 146, 94-102.

Perks, H., Kowalkowski, C., Witell, L., \& Gustafsson, A. (2017). Network orchestration for value platform development. Industrial marketing management, 67, 106-121.

Podsakoff, P. M., MacKenzie, S. B., Lee, J. Y., \& Podsakoff, N. P. (2003). Common method biases in behavioral research: A critical review of the literature and recommended remedies. Journal of applied psychology, 88(5), 879.

Podsakoff, P. M., \& Organ, D. W. (1986). Self-reports in organizational research: Problems and prospects. Journal of management, 12(4), 531-544.

Polim, R., Hu, Q., \& Kumara, S. (2017). Blockchain in megacity logistics. In IIE Annual Conference. Proceedings (pp. 1589-1594). Institute of Industrial and Systems Engineers (IISE).

Prajogo, D., Oke, A., \& Olhager, J. (2016). Supply chain processes: Linking supply logistics integration, supply performance, lean processes and competitive performance. International Journal of Operations and Production Management, 36(2), 220-238.

Prajogo, D., \& Olhager, J. (2012). Supply chain integration and performance: The effects of long-term relationships, information technology and sharing, and logistics integration. International Journal of Production Economics, 135(1), 514-522.

Qrunfleh, S., \& Tarafdar, M. (2014). Supply chain information systems strategy: Impacts on supply chain performance and firm performance. International Journal of Production Economics, 147, 340-350.

Queiroz, M. M., \& Wamba, S. F. (2019). Blockchain adoption challenges in supply chain: An empirical investigation of the main drivers in India and the USA. International Journal of Information Management, 46, 70-82. 
Rai, A., Patnayakuni, R., \& Seth, N. (2006). Firm performance impacts of digitally enabled supply chain integration capabilities. MIS quarterly, 30(2), 225-246.

Ramadan, M., Al-Maimani, H., \& Noche, B. (2017). RFID-enabled smart real-time manufacturing cost tracking system. The International Journal of Advanced Manufacturing Technology, 89(1-4), 969-985.

Rehman, M. U., \& Hussain, A. (2013). Impact of corporate governance on overall firm perofrmance\|. Interdisciplinary Journal of Contemporary Research Business, 4(11), 583-601.

Saberi, S., Kouhizadeh, M., Sarkis, J., \& Shen, L. (2019). Blockchain technology and its relationships to sustainable supply chain management. International Journal of Production Research, 57(7), 2117-2135.

Sahoo, P. K., \& Rath, B. N. (2018). Productivity growth, efficiency change and source of inefficiency: Evidence from the Indian automobile industry. International Journal of Automotive Technology and Management, 18(1), 59-74.

Schifanella, C., Bracciali, A., Benkrid, S., Moussa, R., Badir, H., Lo, M., Bellatreche, L., Preikschat, K., Bohmecke-Schwafert, M., Buchwald, J.-P., \& Stickel, C. (2021). Trusted systems of records based on Blockchain technology - a prototype for mileage storing in the automotive industry. Concurrency and Computation. https://doi.org/10.1002/cpe.5630

Shanley, A. (2017). Could Blockchain improve pharmaceutical supply chain security. Pharmaceutical Technology, 1, s34-s39.

Sideridis, G., Simos, P., Papanicolaou, A., \& Fletcher, J. (2014). Using structural equation modeling to assess functional connectivity in the brain: Power and sample size considerations. Educational and psychological measurement, 74(5), 733-758.

Singh, M., \& Kim, S. (2018). Branch based blockchain technology in intelligent vehicle. Computer Networks, 145, 219-231.

Sobel, M. E. (1982). Asymptotic confidence intervals for indirect effects in structural equation models. Sociological Methodology, 13, 290-312.

Subramanian, N., Chaudhuri, A., Kayikci Y. (2020). Blockchain and Supply Chain Logistics: Evolutionary Case Studies. London: Palgrave. ISBN 978-3-030-47530-7.

Sundram, V. P. K., Bahrin, A. S., Munir, A., Z. B., and Zolait, A. H. (2018). The effect of supply chain information management and information system infrastructure: The mediating role of supply chain integration towards manufacturing performance in Malaysia. Journal of Enterprise Information Management, 31(5), 751-770.

Teece, D. J., Pisano, G., \& Shuen, A. (1997). Dynamic capabilities and strategic management. Strategic Management Journal, 18(7), 509-533.

Upadhyay, A., Ayodele, J. O., Kumar, A., \& Garza-Reyes, J. A. (2021). A review of challenges and opportunities of blockchain adoption for operational excellence in the UK automotive Industry. Journal of Global Operations and Strategic Sourcing, 14(1), 7-60. https://doi.org/10.1108/ JGOSS-05-2020-0024

Van Hoek, R. I. (1999). Postponement and the reconfiguration challenge for food supply chains. Supply Chain Management: An International Journal, 4(1), 18-34.

Vanderhaeghe, A., \& De Treville, S. (2003). How to fail at flexibility. Supply Chain Forum: An International Journal, 4(1), 64-67.

Vanpoucke, E., Vereecke, A., \& Muylle, S. (2017). Leveraging the impact of supply chain integration through information technology. International Journal of Operations and Production Management, $37(4), 510-530$.

Venkatraman, N., \& Grant, J. H. (1986). Construct measurement in organizational strategy research: A critique and proposal. Academy of management review, 11(1), 71-87.

Viryasitavat, W., Xu, D., Bi, L., Z., \& Sapsomboon, A. (2020). Blockchain-based business process management (BPM) framework for service composition in industry 4.0. Journal of Intelligent Manufacturing, 31, 1737-1748. https://doi.org/10.1007/s10845-018-1422-y.

Wang, R., Lin, Z., \& Luo, H. (2019). Blockchain, bank credit and SME financing. Quality and Quantity, 53(3), 1127-1140.

Weber, I., Xu, X., Riveret, R., Governatori, G., Ponomarev, A., \& Mendling, J. (2016). Untrusted business process monitoring and execution using Blockchain. In International conference on business process management (pp. 329-347). Springer.

White, G. R. (2017). Future applications of Blockchain in business and management: A Delphi study. Strategic Change, 26(5), 439-451. 
Williamson, O. E. 1989. In: R. Schmalensee \& R. D. Willig (Eds.), Transaction Cost Economics. Handbook of Industrial Organization, Vol. 1. Elsevier Science Publishers B.V., North Holland, Amsterdam, pp. 136-178.

Winnesota, (2017). How Blockchain Is Revolutionizing The World Of Transportation and Logistics. Available at: https://www.winnesota.com/blockchain

Wipro. (2017). Wipro Joins Hyperledger to Catalyze Collaboration on Enterprise-Grade Blockchain Solutions. Available at: https://www.wipro.com/newsroom/press-releases/2017/wipro-joins-hyperledgerto-catalyze-collaboration-on-enterprise-grade-blockchain-solutions/. Retrieved on 2 December 2017.

Wolf, E. J., Harrington, K. M., Clark, S. L., \& Miller, M. W. (2013). Sample size requirements for structural equation models: An evaluation of power, bias, and solution propriety. Educational and Psychological Measurement, 73(6), 913-934.

Wong, C. Y., Boon-Itt, S., \& Wong, C. W. (2011). The contingency effects of environmental uncertainty on the relationship between supply chain integration and operational performance. Journal of Operations management, 29(6), 604-615.

Xu, X., He, P., Xu, H., \& Zhang, Q. (2017). Supply chain coordination with green technology under capand-trade regulation. International Journal of Production Economics, 183, 433-442.

Yang, C., Lan, S., Shen, W., Huang, G. Q., Wang, X., \& Lin, T. (2017). Towards product customization and personalization in IoT-enabled cloud manufacturing. Cluster Computing, 20(2), 1717-1730.

Yu, Z., Ouyang, J., Li, S., \& Peng, X. (2017). Formal modeling and control of cyber-physical manufacturing systems. Advances in Mechanical Engineering, 9(10), 1-12.

Yu, Y., Xiong, W., \& Cao, Y. (2015). A conceptual model of supply chain risk mitigation: The role of supply chain integration and organizational risk propensity. Journal of Coastal Research, 73(sp1), 95-98.

Zhao, X., Huo, B., Flynn, B. B., \& Yeung, J. H. Y. (2008). The impact of power and relationship commitment on the integration between manufacturers and customers in a supply chain. Journal of Operations Management, 26(3), 368-388.

Zhao, X., Huo, B., Selen, W., \& Yeung, J. H. Y. (2011). The impact of internal integration and relationship commitment on external integration. Journal of operations management, 29(1-2), 17-32.

Zhou, L., Chong, A. Y., \& Ngai, E. W. (2015). Supply chain management in the era of the internet of things. International Journal of Production Economics, 159, 1-3.

Zhu, Q., Feng, Y., \& Choi, S. B. (2017). The role of customer relational governance in environmental and economic performance improvement through green supply chain management. Journal of Cleaner Production, 155(2), 46-53.

Zou, J., Ye, B., Qu, L., Wang, Y., Orgun, M. A., \& Li, L. (2018). A Proof-of-Trust Consensus Protocol for Enhancing Accountability in Crowdsourcing Services. IEEE Transactions on Services Computing, $1-14$.

Publisher's Note Springer Nature remains neutral with regard to jurisdictional claims in published maps and institutional affiliations.

\section{Authors and Affiliations}

\section{Sachin S. Kamble ${ }^{1}$ Angappa Gunasekaran ${ }^{2}$. Nachiappan Subramanian ${ }^{3}[$. Abhijeet Ghadge $^{4} \cdot$ Amine Belhadi $^{5} \cdot$ Mani Venkatesh $^{6}$}

Sachin S. Kamble

Sachin.kamble@edhec.edu

Angappa Gunasekaran

agunasekaran@csub.edu

Abhijeet Ghadge

Abhijeet.Ghadge@cranfield.ac.uk

Amine Belhadi

Belhadi.amine@ outlook.com

Mani Venkatesh

m.venkatesh@montpellier-bs.com 


\section{EDHEC Business School, Lille, France}

2 School of Business and Public Administration, California State University, Bakersfield, CA 93311-1022, USA

3 University of Sussex Business School, Brighton BN19SL, UK

4 Cranfield School of Management, Cranfield, Bedfordshire MK43 0AL, UK

5 Cadi Ayyad University, Marrakech, Morocco

6 Montpellier Business School, University of Montpellier, Montpellier Research in Management, Montpellier, France 